\title{
Job Stress and Cardiovascular Health: Is There a Connection?
}

\author{
Fernando Henpin Yue Cesena ${ }^{\circ}$ \\ Hospital Israelita Albert Einstein, São Paulo, SP - Brazil \\ Short Editorial related to the article: Ideal Cardiovascular Health and Job Strain: A Cross-Sectional Study from the Amazon Basin
}

The relationship between psychological stress and cardiovascular (CV) disease has been studied for a long time. In particular, the link between job stress and CV outcomes has been a matter of debate. While there are data supporting that job stress increases CV risk, some experts believe that this association is not truly relevant or the results may be biased. ${ }^{1}$

There are many plausible mechanisms by which job stress may increase the likelihood of CV events, including augmentation of autonomic tonus and predisposition to risk behaviors, such as physical inactivity, unhealthy diet, and smoking. ${ }^{2}$

In this context, the study by Muniz e al. ${ }^{3}$ published in this issue of Arquivos Brasileiros de Cardiologia is very welcome. The authors sought to investigate, in a cross-sectional study, the prevalence of ideal CV health and the influence of job stress on CV health among 478 employees from a university in Rio Branco, Acre, Brazil.

$\mathrm{CV}$ health was determined by a standard method proposed by the American Heart Association, ${ }^{4}$ which considers variables related to lifestyle and traditional risk factors. Job stress was assessed by the classic model proposed by Karasek, ${ }^{5}$ which is the method most frequently used in similar studies. According to this model, high job strain occurs when there is a high psychological demand associated with low control over the demands.

Three main aspects of the study by Muniz et al. ${ }^{3}$ can be highlighted.

First, it is always good and enriching to see scientific data from a remote place, underrepresented in the cardiological literature, being reported in a medical journal.

Second, and this is alarming, the vast majority of individuals (91\%) were considered to have poor CV health, and no one had ideal CV health. ${ }^{3}$ One can say that criteria for ideal CV health are too stringent. It can also be said that CV health was not properly evaluated (for instance, information on high blood cholesterol and diabetes was self-reported). Also, the study has limited external validation, as it recruited employees from a single university (65\% men), not really representing the general population. Even though, the overall poor CV health reported in this study surpassed the expectations, as

\section{Keywords}

Cardiovascular Diseases; Occupational Stress; Stress, Psychological, Risk Factors.

Mailing Address: Fernando Henpin Yue Cesena •

Hospital Israelita Albert Einstein - Avenida Brasil, 953. Postal Code 01431-000, São Paulo, SP - Brazil

E-mail: fernando.cesena@einstein.br, cesenaf@gmail.com

DOI: $10.5935 / a b c .20190030$ the authors pointed out. ${ }^{3}$ This finding is, per se, a headline to be carefully interpreted by the general population, healthcare providers, and health authorities.

Third, the study brings some insights into the relationship between work stress and CV health. The authors report an association between job strain and poor CV health that did not reach statistical significance. However, high job strain was related to obesity and poor diet. ${ }^{3}$

It must be acknowledged, as the authors do, that cross-sectional studies can only establish an association and not causality. Therefore, the present study has limited ability to add relevant contribution to the knowledge about the causal relationship between job stress and CV disease. This issue is better assessed by prospective cohort studies, once randomized controlled trials with job stress as an intervention are not feasible or ethical. In this regard, although many cohort studies failed to find a positive association between work stress and coronary heart disease (CHD), ${ }^{2}$ many other studies and meta-analyses did find a significant relationship between job strain and CV outcomes, ${ }^{1,6}$ as well as with diabetes, smoking, physical inactivity, and obesity. ${ }^{7,8}$

For instance, Kivimäki et al. reported that job strain increased the risk of CHD by $23 \%$ in a meta-analysis including almost 200,000 individuals from published and unpublished studies, an attempt to avoid publication bias. ${ }^{6}$

Long working hours ( $\geq 55$ hours a week), a pattern frequently correlated with job stress, were also shown to increase the risk of CHD by 1.12-fold and the risk of stroke by 1.21 -fold in a large meta-analysis. ${ }^{9}$

Therefore, it seems reasonable to accept job strain as a risk factor for CV disease or, at least, a factor that may increase the risk of $\mathrm{CV}$ events by exacerbating traditional risk factors or by facilitating an unhealthy lifestyle.

Efforts should be made to deepen knowledge in this field. Future research should focus on the nuances of the relationship between job stress and CV health. Identifying types and patterns of work more closely related to CV disease may reveal targets for preventive interventions, that can be tested in clinical trials or implemented in the workplace.

The study by Muniz et al. ${ }^{3}$ has the merit of shedding light on a relevant, frequently underappreciated aspect of $\mathrm{CV}$ prevention. In the contemporary world characterized by a highly competitive professional environment, job stress is very prevalent and its relevance increases in times of economic crisis. Both employers and employees should be aware of the potential unhealthy consequences of job strain. Healthcare providers should address this issue when talking with patients about lifestyle and CV prevention. Health authorities should not neglect this topic. The ultimate goal is to reduce the burden of job stress on CV disease. 


\section{References}

1. Kivimäki M, Kawachi I. Work Stress as a risk factor for cardiovascular disease Curr Cardiol Rep. 2015;17(9):630.

2. Sara JD, Prasad M, Eleid MF, Zhang M, Widmer RJ, Lerman A. Association between work-related stress and coronary heart disease: a review of prospective studies through the Job Strain, Effort-Reward Balance, and Organizational Justice Models. J Am Heart Assoc. 2018;7(9):pii.e008073

3. Muniz DD, Siqueira KS, Cornell CT, Fernandes-Silva MM, Muniz PT, Silvestre OM. Ideal cardiovascular health and job strain: a cross-sectional study from the Amazon Basin. Arq Bras Cardiol. 2019; 112(3):260-268.

4. Lloyd-Jones DM, Hong Y, Labarthe D, Mozaffarian D, Appel LJ, Van Horn $\mathrm{L}$, et al. Defining and setting national goals for cardiovascular health promotion and disease reduction: the American Heart Association's strategic Impact Goal through 2020 and beyond. Circulation. 2010;121(4):586-613.
5. Karasek R, Baker D, Marxer F, Ahlbom A, Theorell T. Job decision latitude, job demands, and cardiovascular disease: a prospective study of Swedish men. Am J Public Health. 1981;71(7):694-705.

6. Kivimäki M, Nyberg ST, Batty GD, Fransson El, Heikkilä K, Alfredsson L, et al. Job strain as a risk factor for coronary heart disease: a collaborative metaanalysis of individual participant data. Lancet. 2012;380(9852):1491-7.

7. Nyberg ST, Fransson El, Heikkilä K, Alfredsson L, Casini A, Clays E, et al. Job strain and cardiovascular disease risk factors: meta-analysis of individual-participant data from 47,000 men and women. PLoS One. 2013;8(6):e67323.

8. Nyberg ST, Fransson El, Heikkilä K, Ahola K, Alfredsson L, Bjorner JB, et al. Job strain as a risk factor for type 2 diabetes: a pooled analysis of 124,808 men and women. Diabetes Care. 2014;37(8):2268-75.

9. Virtanen M, Kivimäki M. Long Working Hours and Risk of Cardiovascular Disease. Curr Cardiol Rep. 2018;20(11):123. 